\section{Commentary: Tick-tock}

Jennifer Nishimura, MD, and

Nahush A. Mokadam, MD

Circadian was a term coined in the 1950s by Dr Franz Halberg, a founder of the field of chronobiology. In a review article, Halberg and colleagues ${ }^{1}$ wrote, "It is hard, however, to single out any field to which circadians are not relevant, whether to scientists and other professionals, or even the proverbial person on the street." Research in chronobiology has made its way into medical practice, from bench to bedside. It has influenced policy to make changes in dayto-day life, such as an endorsement from American Academy of Pediatrics to delay school start times for adolescents to optimize sleep. ${ }^{2}$ Although many decades of research in this field exist, including research awarded the Nobel Prize in Physiology or Medicine in 2017, its relevance in the daily practice of cardiac surgery is unclear.

"Heart surgery survival chances "better in the afternoon'." "3 That was one of many interesting headlines from mainstream media that was generated after Montaigne and colleagues ${ }^{4}$ published a study in Lancet, which focused on the chronobiology of patients, cardiac surgery times, and outcomes. ${ }^{3-5}$ This study found that there was a higher incidence of major adverse cardiovascular events in patients undergoing elective surgical aortic valve replacement (AVR) with or without concomitant coronary artery bypass grafting (CABG) in the morning versus afternoon, which was largely driven by higher immediate perioperative myocardial infarction and acute heart failure in that group.

In this edition of The Journal, Nemeth and colleagues ${ }^{6}$ referenced Montaigne and colleagues' article, ${ }^{4}$ calling it provocative and sought to investigate if different start times were associated with different outcomes. Nemeth and colleagues' comprehensive and robust retrospective analyses

From the Division of Cardiac Surgery, Department of Surgery, The Ohio State University Wexner Medical Center, Columbus, Ohio.

Disclosures: Dr Mokadam is a consultant and investigator for Abbott, Medtronic, Carmat, and SynCardia. Dr Nishimura has nothing to disclose with regard to commercial support.

Received for publication Jan 8, 2020; revisions received Jan 8, 2020; accepted for publication Jan 13, 2020; available ahead of print Jan 31, 2020.

Address for reprints: Nahush A. Mokadam, MD, Division of Cardiac Surgery, The Ohio State University Wexner Medical Center, N-825 Doan Hall, 410 West 10th Ave, Columbus, OH 43210 (E-mail: Nahush.Mokadam@osumc.edu).

J Thorac Cardiovasc Surg 2021;162:68-9

$0022-5223 / \$ 36.00$

Copyright (c) 2020 by The American Association for Thoracic Surgery

https://doi.org/10.1016/j.jtcvs.2020.01.027

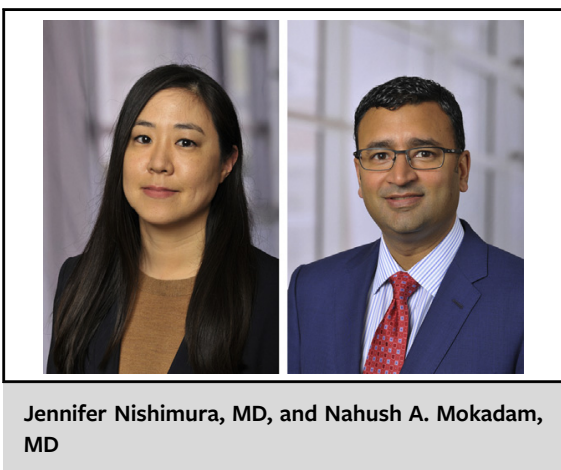

CENTRAL MESSAGE

Working in sync with circadian rhythm and chronobiology has the potential to improve patient outcomes in cardiac surgery, but more research is needed.

examined the impact of start times in the morning (6:309:00 AM) versus afternoon (12:00-2:30 PM) on the surgical outcomes of isolated CABG and isolated AVR using propensity score matching. Patients from 11 cardiac surgery programs were included and found no difference in operative mortality or major morbidity in CABG or AVR. Axtell and colleagues ${ }^{7}$ recently reported no difference in perioperative outcomes, including 30-day mortality and composite morbidity, associated with starting nonemergency cardiac surgical cases after 3 PM. There are many other studies regarding the timing of cardiac surgery and outcomes reporting similar results, one of which even evaluated outcomes in relation to moon phase..$^{8-10}$

Have we learned anything? We have Nobel Prize-earning research that emphasizes circadian rhythms and initial data on cardiac surgery that support them. We now have some data that suggest we can safely overcome them. Elective cardiac operations will happen in the morning and afternoon for the foreseeable future-that is our cultural workday. Patient and provider chronobiology should not be ignored, but perhaps we should ask different questions and incorporate topics such as burnout, satisfaction, retention, and morale. Although intact patient outcomes may be reassuring, we should still strive to create an environment that respects what we know about our internal clock.

\section{References}

1. Halberg F, Cornélissen G, Katinas G, Syutkina EV, Sothern RB, Zaslavskaya R, et al. Transdisciplinary unifying implications of circadian findings in the 1950s. $J$ Circadian Rhythms. 2003;1:2. 
2. Adolescent Sleep Working Group; Committee on Adolescence; Council on School Health. School start times for adolescents. Pediatrics. 2014;134:642-9.

3. BBC News Web site. Heart surgery survival chances 'better in the afternoon.' Available at: https://www.bbc.com/news/health-41763958. Accessed December 24, 2019.

4. Montaigne D, Marechal X, Modine T, Coisne A, Mouton S, Fayad G, et al. Daytime variation of perioperative myocardial injury in cardiac surgery and its prevention by Rev-Erb $\alpha$ antagonism: a single-centre propensity-matched cohort study and a randomised study. Lancet. 2018;391:59-69.

5. Heart Surgery May Be Safer in Afternoon Than in Morning. The New York Times. Available at: https://www.nytimes.com/2017/11/01/well/live/heart-surgery-ma y-be-safer-in-afternoon-than-in-morning.html. Accessed December 24, 2019.

6. Nemeth S, Schnell S, Argenziano M, Ning Y, Kurlansky P. Daytime variation does not impact outcome of cardiac surgery: results from a diverse, multi-institutional cardiac surgery network. J Thorac Cardiovasc Surg. 2021; 162:56-67.e44.

7. Axtell AL, Moonsamy P, Melnitchouk S, Jassar AS, Villavicencio MA, D'Alessandro DA, et al. Starting elective cardiac surgery after 3 pm does no impact patient morbidity, mortality, or hospital costs. J Thorac Cardiovasc Surg. September 11, 2019 [Epub ahead of print].

8. Coumbe A, John R, Kuskowski M, Agirbasli M, McFalls EO, Adabag S. Variation of mortality after coronary artery bypass surgery in relation to hour, day and month of the procedure. BMC Cardiovasc Disord. 2011;11:63.

9. Tan PJ, Xu M, Sessler DI, Bashour CA. Operation timing does not affect outcome after coronary artery bypass graft surgery. Anesthesiology. 2009;111:785-9.

10. Yount KW, Lau CL, Yarboro LT, Ghanta RK, Kron IL, Kern JA, et al. Late operating room start times impact mortality and cost for nonemergent cardiac surgery. Ann Thorac Surg. 2015;100:1653-9.

\section{See Article page 56.}

\section{Commentary: Cardiac surgery around the clock!}

\author{
Michele Di Mauro, MD, PhD, \\ Massimiliano Foschi, MD, ${ }^{\mathrm{a}}$ \\ Francesco Amendolara, MD, ${ }^{\mathrm{a}}$ and \\ Antonio M. Calafiore, $\mathrm{MD}^{\mathrm{b}}$
}

Circadian rhythms (CRs) are endogenous autonomous oscillators of physiological activities resulting 24-hour day/night cycles that allow organisms to adapt to a fluctuating environment.

How much CRs could influence the outcome of patients undergoing cardiac surgery in the morning versus in the afternoon is still debated. ${ }^{2-4}$ In this scenario, the multicenter study by Nemeth and colleagues ${ }^{5}$ try to shed light on the actual prognostic role of daytime variation. The strengths of this study are the large size of the cohort and the possibility to subanalyze the most frequent cardiac operations such as coronary artery bypass grafting and aortic valve replacement. The authors clearly demonstrate that undergoing cardiac surgery in morning versus in the afternoon does not influence the outcome. Why is that?

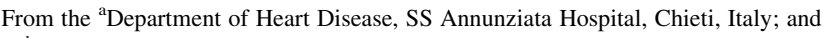
${ }^{\mathrm{b}}$ Department of Cardiac Surgery, Pope John Paul II Foundation, Campobasso, Italy. Disclosures: Authors have nothing to disclose with regard to commercial support.

Received for publication Jan 8, 2020; accepted for publication Jan 13, 2020; available ahead of print Feb 1, 2020.

Address for reprints: Michele Di Mauro, MD, PhD, Department of Heart Disease, SS

Annunziata Hospital, Via dei Vestini, 66100 Chieti, Italy (E-mail: mdimauro1973@gmail.com).

J Thorac Cardiovasc Surg 2021;162:69-70

$0022-5223 / \$ 36.00$

Copyright (c) 2020 by The American Association for Thoracic Surgery

https://doi.org/10.1016/j.jtcvs.2020.01.047
}

\section{Check for updates}

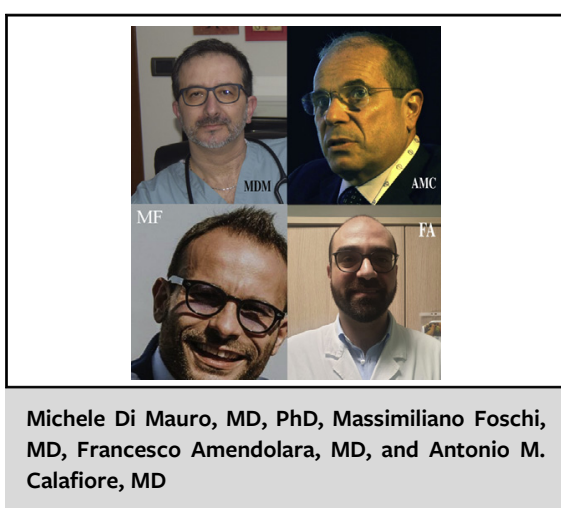

CENTRAL MESSAGE

The outcome of our patients does not depend on the time of day of the operation.

To answer that question, we should be asking how much morning surgery can be different from afternoon surgery in terms of CR desynchronization. The circadian clock can be divided into input pathway, core circadian clock, and output pathway. ${ }^{1}$ A series of external timing cues called synchronizers can reset the circadian clock and place all cells at the same phase of circadian oscillation. Synchronizers include light, feeding, arousal stimuli (eg, social interactions, exercise, and restraint stress), temperature, chemical factors, and oxidative stress. Intriguingly, sedatives, anesthetics, surgical stress, and the intensive care unit environment have all been shown to disrupt the circadian system in patients, altering all the synchronizers independent of the time of day for which surgery is scheduled. ${ }^{6}$ 